\title{
Effects of Repetitive Upsetting Extrusion on the Microstructure and Texture of GWZK124 Alloy under Different Starting Temperatures
}

\author{
Guanshi Zhang ${ }^{1}$, Zhimin Zhang ${ }^{1} * \mathbb{1}$, Yingze Meng ${ }^{2}$, Zhaoming Yan ${ }^{1}$, Xin Che ${ }^{1}$ and Xubin Li ${ }^{1}$ \\ 1 School of Materials Science and Engineering, North University of China, Taiyuan 030051, China \\ 2 College of Mechatronics Engineering, North University of China, Taiyuan 030051, China \\ * Correspondence: b1603012@st.nuc.edu.cn; Tel.: +86-351-392-1778
}

Received: 14 July 2019; Accepted: 30 July 2019; Published: 31 July 2019

\begin{abstract}
The effects of repetitive upsetting extrusion under different starting temperatures on the microstructure and texture of GWZK124 alloy were investigated. The results clearly showed that the particles and second phases induced dynamic recrystallization (DRX), which can be explained by the particle-stimulated nucleation (PSN) mechanism. It was shown that grain refinement during repetitive upsetting extrusion (RUE) is dominated by a complicated combination of continuous dynamic recrystallization and discontinuous dynamic recrystallization. The RUEed alloys under different starting temperatures exhibited a bimodal microstructure comprising fine DRXed grains with weak texture and coarse deformed grains with strong texture. The DRXed grains could weaken the texture. As the RUE starting temperature decreased, the average grain size increased and the volume fraction of DRXed grains decreased.
\end{abstract}

Keywords: repetitive upsetting extrusion; Mg-Gd-Y-Zn-Zr; microstructure; dynamic recrystallization; texture

\section{Introduction}

Magnesium $(\mathrm{Mg})$ alloys have been applied in various structural components in the aerospace, automotive and aircraft industries owing to their good damping capacity, low density, excellent creep resistance and so on [1-3]. Compared to other conventional structural alloys, $\mathrm{Mg}$ alloy has poor strength and inferior ductility at room temperature (RT) due to its hexagonal close-packed (hcp) lattice structure [4-7]. Grain refinement is one obvious way to simultaneously improve its strength and ductility. Repetitive upsetting extrusion (RUE), a kind of severe plastic deformation (SPD) technique, is attractive for its potential to fabricate high volumes of blanks [8], which has significant application in industry. Furthermore, it is highly adaptable for refining grains of hard-to-deform metal such as Mg alloy because it enables three-dimensional compression stresses to be exerted during deformation, while avoiding sample cracking [9]. Previous researches on materials such as LY12 [10], AZ61 [11] and AZ91D [12], have revealed that RUE processing can refine grains and the second phases.

In recent years, many researchers have been working hard to develop novel alloy compositions to improve the strength and ductility of $\mathrm{Mg}$ alloy, and to achieve light weight applications. Rare earth (RE) bearing Mg alloys are noted for their excellent properties at high temperature and RT due to the formation of heat-resistant precipitates [13]. Among kinds of RE Mg alloys, Mg-RE-Zn alloys have been the focus of numerous researchers owing to their reasonable ductility and superior high strength [14]. It is believed that the new and unique long-period stacking ordered (LPSO) phases in Mg-Gd-Y-Zn-Zr alloys contribute to improving both their ductility and strength [15,16]. Moreover, the kink mechanism of intragranular LPSO phases can accommodate strain, which can also contribute to 
the excellent properties of the Mg-Gd-Y-Zn-Zr alloys [17-20]. Recently, the ultimate tensile strength (UTS) of Mg-1.8Gd-1.8Y-0.7Zn-0.2Zr (at \%) alloy reached $542 \mathrm{MPa}$, subsequent to its preparation by hot extrusion followed by aging treatment [21]. During the aging treatment, the fine and dense precipitates appeared around the grain boundaries of the dynamically recrystallized grains, which was the main reason for its excellent properties. Xu et al. produced Mg-8.2Gd-3.8Y-1.0Zn-0.4Zr (wt \%) alloys by hot rolling and aging treatment, resulting in the UTS increasing to $517 \mathrm{MPa}$ and the fracture elongation increasing to $4.5 \%$ [22].

The aim of this article is to demonstrate the effects of RUE on the microstructure and texture of GWZK124 alloy under different starting temperatures. In addition, the grain refinement mechanism of RUE on the as-homogenized GWZK124 alloy was investigated.

\section{Materials and Methods}

The composition of the studied alloy was Mg-12.1Gd-4.0Y-2.2Zn-0.34Zr (wt \%), which is denoted here as GWZK124. A cylindrical ingot measuring $3000 \mathrm{~mm}$ in length and $330 \mathrm{~mm}$ in diameter was prepared by the semi-continuous casting method. The positions of all of the samples were at the center of the ingot, and these cylinders were $\varphi 20 \mathrm{~mm} \times 50 \mathrm{~mm}$. Subsequent homogenization was performed at a temperature of $520^{\circ} \mathrm{C}$ for $16 \mathrm{~h}$ and then quenched in water at a temperature of $70{ }^{\circ} \mathrm{C}$ to obtain uniformity in the initial microstructure. The schematic of the RUE is presented in Figure 1 [10]. The RUE processing combined upsetting and extrusion and the two processes were alternated in each pass, which allowed for the accumulative strain. The RUE dies were preheated to the given temperature in the resistance furnace, and then reserved for $30 \mathrm{~min}$ before RUE processing. The as-homogenized samples were preheated at the given temperature for $10 \mathrm{~min}$ before RUE processing to homogenize the temperature of the samples. To achieve relatively homogeneous deformation, a graphite-based mixture was used as the lubricant.

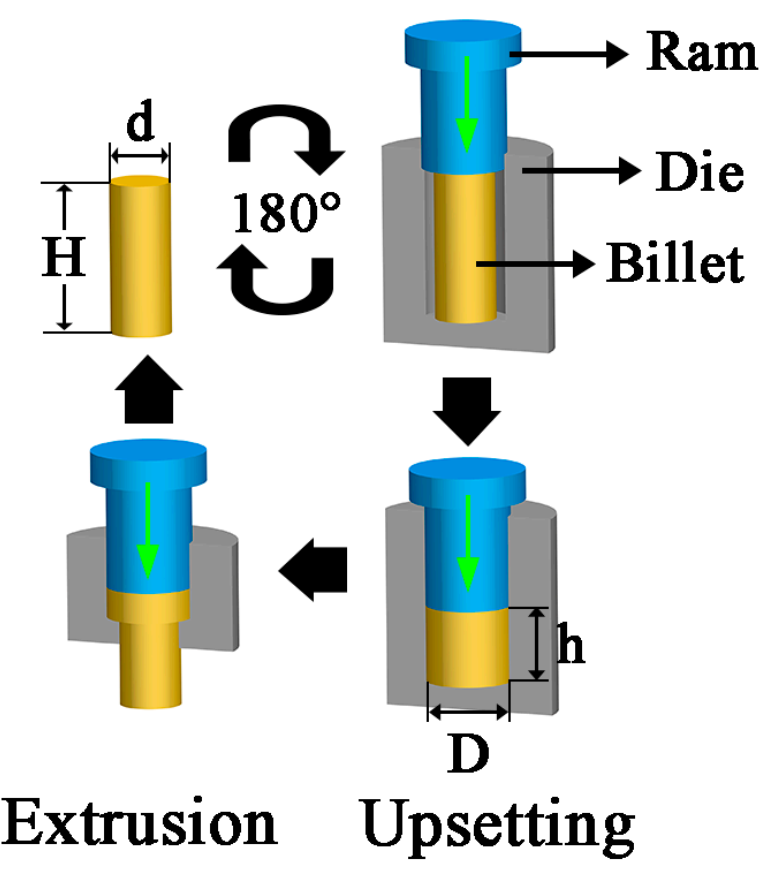

Figure 1. The principle of the repetitive upsetting extrusion (RUE) processing.

These as-homogenized samples were RUEed on an Instron 3382 tensile machine equipped with a resistance furnace at a ram speed of $4 \mathrm{~mm} / \mathrm{min}$ and they were divided into 3 groups. The first group was RUEed under decreasing temperatures from $480{ }^{\circ} \mathrm{C}$ to $440{ }^{\circ} \mathrm{C}$ with a drop of $20^{\circ} \mathrm{C}$ every one RUE pass (defined as sample \#1). The second group was RUEed under decreasing temperatures from $460^{\circ} \mathrm{C}$ to $440{ }^{\circ} \mathrm{C}$ with a drop of $10^{\circ} \mathrm{C}$ every one RUE pass (defined as sample \#2). The third 
group was RUEed at $440^{\circ} \mathrm{C}$ (defined as sample \#3). The schematic illustration of the experimental procedures for sample \#1, \#2 and \#3 are shown in Figure 2. The temperature of the resistance furnace was monitored using a K-type thermocouple. The magnitude of the accumulative strain used the following formula: $\sum \Delta \varepsilon=4 n \times \ln (\mathrm{D} / \mathrm{d})$ (where $\mathrm{n}$ is the number of passes through the upsetting and extrusion dies) [23]. In this research, D and d were $28 \mathrm{~mm}$ and $20 \mathrm{~mm}$, respectively. RUE was carried out up to a maximum accumulative strain of $\sum \Delta \varepsilon=4.04$, i.e., a total of three passes. All samples were quenched immediately in the water at RT after deformation.

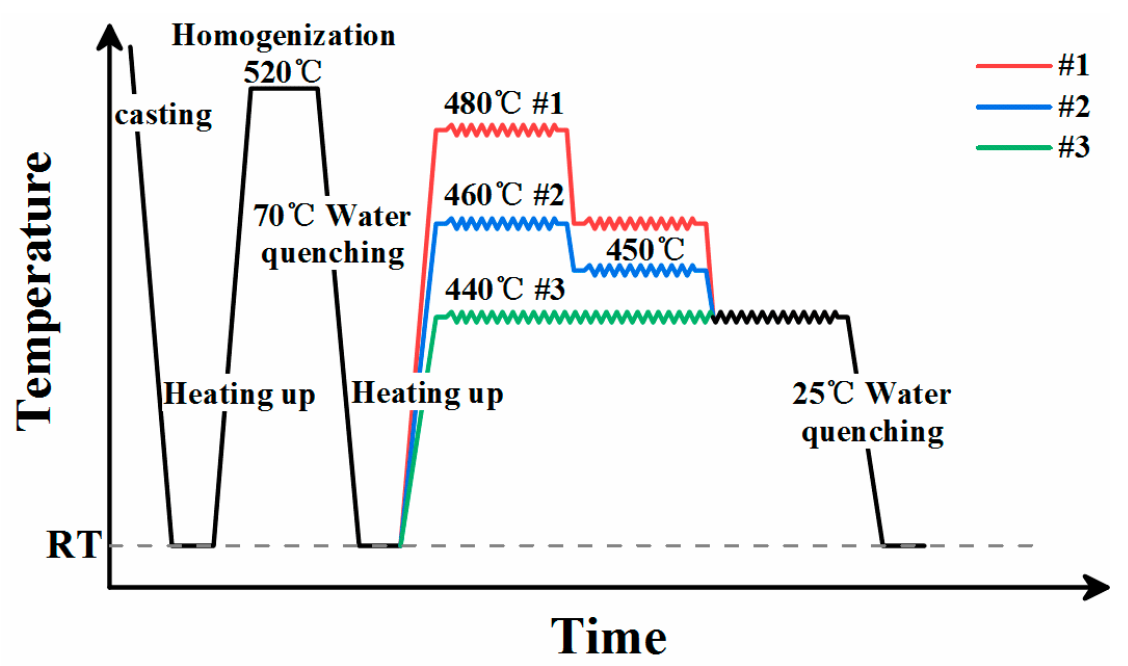

Figure 2. The schematic illustrations of experimental procedures for sample \#1, \#2 and \#3.

For the phase analysis, X-ray diffraction (XRD) was performed on the SmartLab, in the $2 \theta$ diffraction angle from $20^{\circ}$ to $90^{\circ}$. To evaluate the homogeneity of the RUEed samples, the edge and the center of the samples along the longitudinal section were observed. The evolved microstructures were prepared for optical microscopy (OM), scanning electron microscopy (SEM, Hitachi SU5000, Tokyo, Japan) and electron backscatter diffraction (EBSD, EDAX Inc., Mahwah, NJ, USA). OM observation was carried out using the Zeiss Axio Imager A2m (Zeiss, Oberkochen, Germany). To evaluate the grain size, the samples were etched in a solution of $3 \mathrm{~mL}$ distilled water, $2 \mathrm{~g}$ picric acid, $2 \mathrm{~mL}$ acetic acid and $20 \mathrm{~mL}$ ethanol. The average size and volume fractions of grains were simply measured through Image-Pro Plus 6.0 software based on OM images. EBSD collection was carried out using a Hitachi SU5000 SEM equipped with an EDAX-TSL EBSD system. The EBSD data were analyzed using orientation imaging microscopy (OIM) software version 7.3 to obtain the texture and other information about the samples. DRXed grains were defined as grains with an average grain size of $\leq 10 \mu \mathrm{m}$.

\section{Results and Discussion}

\subsection{Microstructures of the As-Cast and As-Homogenized GWZK124 Alloys}

The OM and back-scattered electron (BSE) micrographs of the as-cast GWZK124 alloy are shown in Figure 3a,c. The as-cast alloy consisted of $\alpha$-Mg matrix and network eutectics. Some oriented fine-lamellar phases could be seen inside the grains, and these intragranular fine-lamellar phases were considered as the 14H-LPSO phases [24]. XRD patterns demonstrated the existence of $\alpha$-Mg matrix, $\mathrm{Mg}_{12}(\mathrm{Gd}, \mathrm{Y}) \mathrm{Zn}$ and $\mathrm{Mg}_{5}(\mathrm{Gd}, \mathrm{Y}, \mathrm{Zn})$ phases in the as-cast alloy (Figure 3e). After homogenization at $520{ }^{\circ} \mathrm{C}$ for $16 \mathrm{~h}$ (Figure $3 \mathrm{~b}, \mathrm{~d}$ ), the alloy consisted of $\alpha-\mathrm{Mg}$ matrix with a grain size of $100 \mu \mathrm{m}$ and interdendritic block-shaped phases. In comparison with the as-cast alloy, there was no obvious grain growth for the as-homogenized alloy owing to the pinning effect produced by the block-shaped phases at the triple junctions. The network of grain boundary eutectics and fine-lamellar phases disappeared because of the dissolution of Gd, $\mathrm{Y}$ and Zn elements. Many block-shaped phases remained, 
which indicated that the block-shaped phases had higher thermal stability. It could be verified that $\mathrm{Mg}_{5}(\mathrm{Gd}, \mathrm{Y}, \mathrm{Zn})$ belonged to the network phase and $\mathrm{Mg}_{12}(\mathrm{Gd}, \mathrm{Y}) \mathrm{Zn}$ belonged to the block-shaped phase (Figure 3a,b). Previously, it has been found that the $\mathrm{Mg}_{12}(\mathrm{Gd}, \mathrm{Y}) \mathrm{Zn}$ was the 14H-LPSO phase [25]. It could be seen that the $\alpha$-Mg matrix occupied the dark contrast areas, and the grey block-shaped phases were distributed around the grain boundary (Figure $3 \mathrm{~d}$ ).
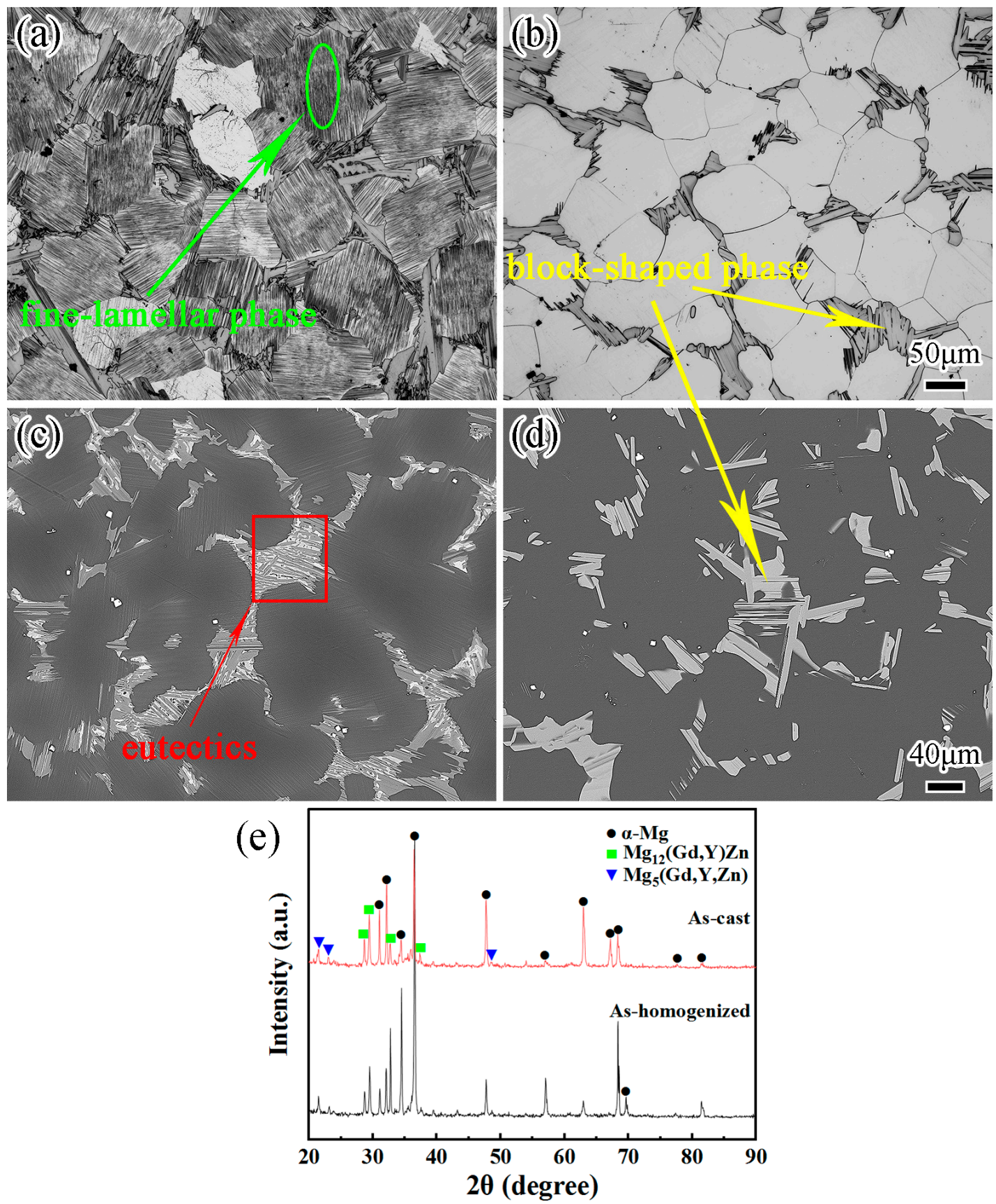

Figure 3. Optical microscopy (OM) micrographs of the GWZK124 alloys: (a) as-cast; (b) as-homogenized, and their corresponding back-scattered electron (BSE) micrographs (c,d). XRD patterns of GWZK124 alloys in as-cast and as-homogenized states (e).

\subsection{Microstructures of the RUEed Alloys under Different Starting Temperatures}

Figure 4 shows the OM and corresponding BSE images of the edge and the center of the samples along the RUE direction. It can be easily observed that the microstructure of the samples exhibited a 
special bimodal distribution in which deformed grains distributed along the RUE direction and small grains had an average grain size of about $3.8 \mu \mathrm{m}$. Many oriented fine-lamellar phases were formed inside the grains, and some particle phases were found at the triple points of DRXed grain boundaries, indicating that dynamic precipitation happened during RUE processing. These fine-lamellar phases and particle phases were the $14 \mathrm{H}-\mathrm{LPSO}$ and $\mathrm{Mg}_{5}(\mathrm{Gd}, \mathrm{Y}, \mathrm{Zn})$, respectively [26]. Meanwhile, it could also be seen that some interdendritic block-shaped phases were broken up and heterogeneously distributed around the grain boundary. The dynamic recrystallization (DRX) was believed to occur around the grain boundaries of the deformed grains and broken second phases, where dislocations were accumulated during deformation. It is widely known that the particles and second phases induce DRX, which can be explained by the particle-stimulated nucleation (PSN) mechanism [27]. Because of the inhibition of dislocation displacement, the dislocations piled up between the block-shaped phases and matrix. It is supposed that the PSN involved a rapid sub-grain boundaries migration in the areas around the block-shaped phases during RUE processing. The sub-grain boundaries absorbed the piling up dislocations during migration, increased the misorientation and gradually formed high-angle grain boundaries (HAGBs), thus realizing the DRX process. The grain measurement showed that the average grain size decreased to about $45 \pm 5 \mu \mathrm{m}$ in the center of the sample \#1 and to about $27 \pm 3 \mu \mathrm{m}$ at the edge (Figure $4 \mathrm{a}, \mathrm{g}$ ).

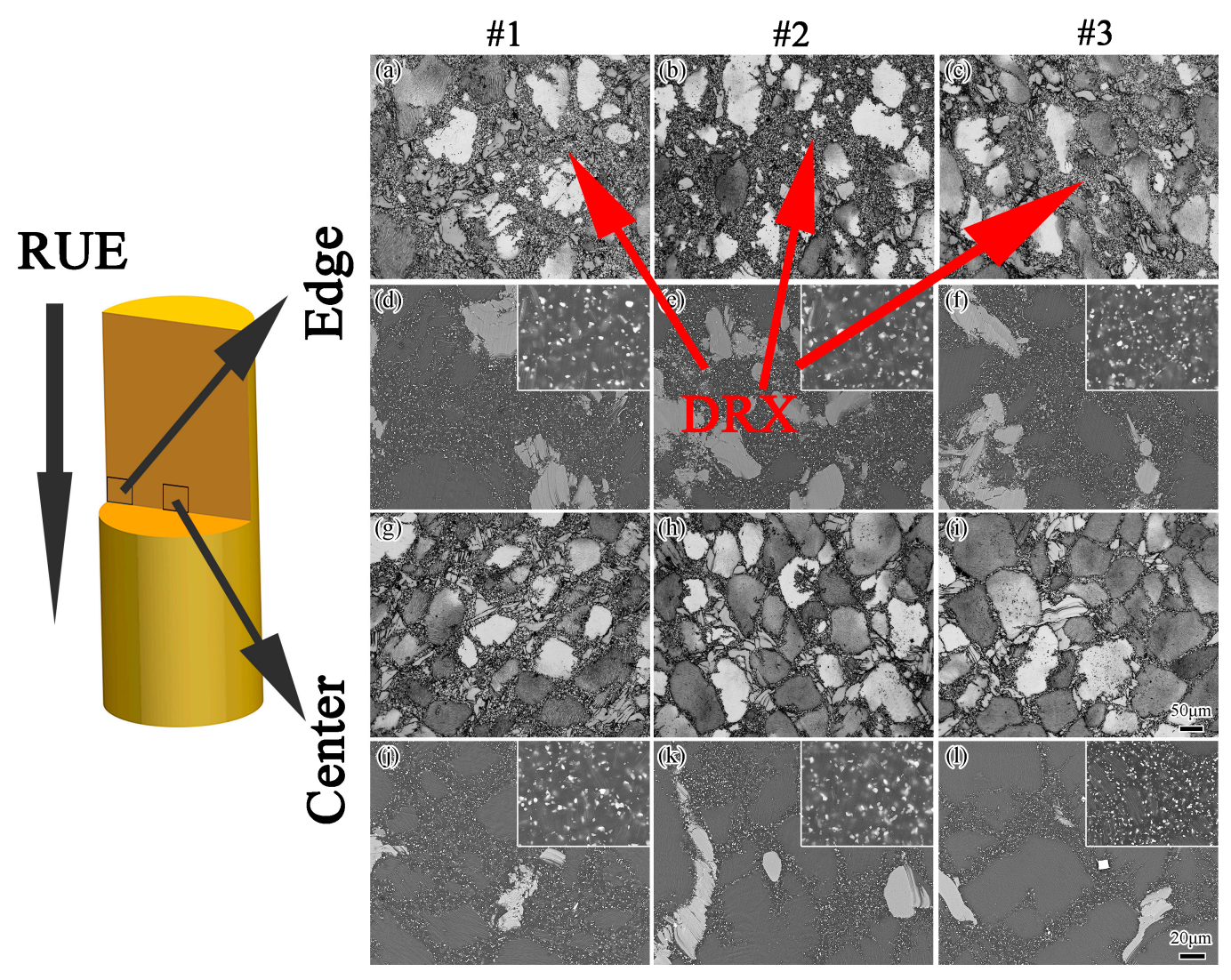

Figure 4. OM $(\mathbf{a}-\mathbf{c}, \mathbf{g}-\mathbf{i})$ and corresponding BSE $(\mathbf{d}-\mathbf{f}, \mathbf{j}-\mathbf{l})$ micrographs of the edge and the center of the samples RUEed under different starting temperatures. The magnified images of the particle phases are shown in the upper right corner.

Under different starting temperatures, the grain size distribution was still heterogeneous with fine grains along the grain boundaries, and some initial coarse grains (Figure 4). It could also be seen that lower starting temperatures enhanced the precipitation of the particle phases (Figure $4 \mathrm{~d}, \mathrm{f}$ ). When the RUE starting temperatures were decreased, there was insufficient stored energy in the alloy, thus the degree of DRX was decreased. Therefore, the deformation temperature played an important role in the 
formation of DRX. The deformation temperature had an effect on the dislocation density, dislocation migration and the formation of sub-grain structures [28]. The DRXed grain size did not show much difference despite the existence of different volume fractions of DRXed grains. The non-uniformity of deformation with different starting temperatures was observed, for example, the sample from the center of the longitudinal section (Figure $4 \mathrm{~h}, \mathrm{i}$ ) exhibited a coarser structure than that taken from the edge (Figure $4 b, c)$. As the RUE starting temperature decreased, the grain size gradually increased.

\subsection{Microtexture Evolution of the RUEed Alloys}

For the purpose of discussing the mechanism of DRX and texture evolution, the RUEed alloys were investigated using EBSD. Figure 5 exhibits the OIM maps close to the edge of the alloys RUEed under different starting temperatures, however, only $\alpha-\mathrm{Mg}$ could be analyzed and the black areas or irregular aggregation of dots represent the second phases with low confidence index values because the OIM system could not analyze their Kikuchi diffraction patterns [17]. Black lines indicate HAGBs larger than $15^{\circ}$ and white lines indicate low-angle grain boundaries (LAGBs) between $2{ }^{\circ} \mathrm{C}$ and $15^{\circ}$.

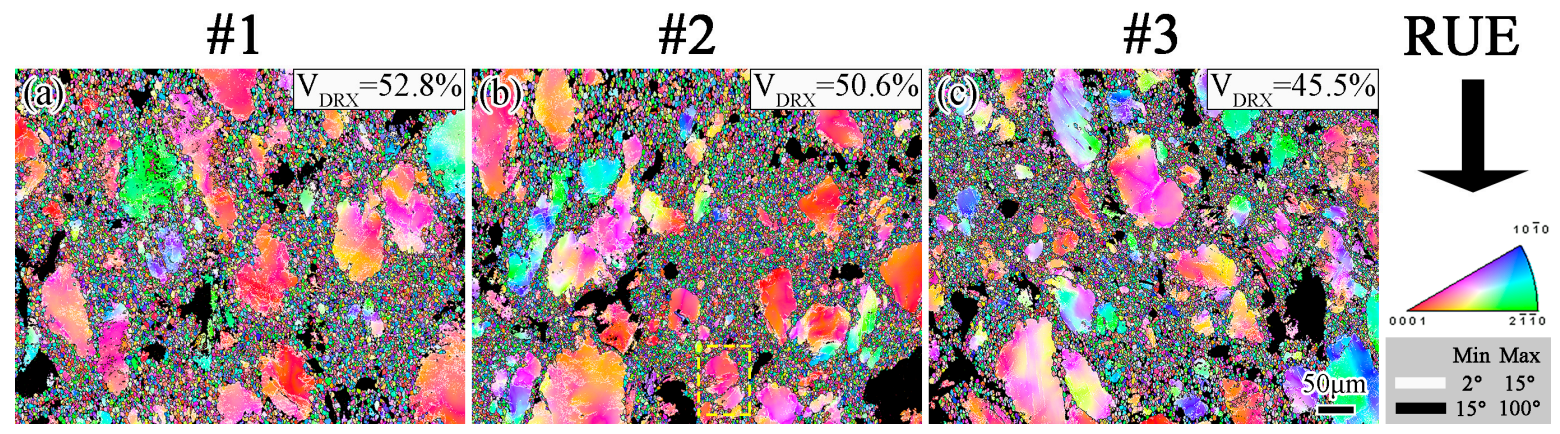

Figure 5. OIM maps of the edge of sample \#1 (a), \#2 (b) and \#3 (c). The color-code of the stereographic triangle shows the crystallographic orientation of hcp crystal. Black lines indicate HAGBs larger than $15^{\circ}$ and white lines indicate low-angle grain boundaries (LAGBs) between $2^{\circ}$ and $15^{\circ}$.

The deformation bands and twins were commonly observed in the Mg-Gd-Y alloys [29] and $\mathrm{Mg}-\mathrm{Al}-\mathrm{Zn}$ alloys [30-32] deformed under other deformation conditions. However, they could not be seen in the RUEed alloys in this study. Hence, grain refinement was mainly caused by DRX. The DRX mechanism in Mg alloys could be classified into two groups: continuous dynamic recrystallization (CDRX) and discontinuous dynamic recrystallization (DDRX). In accordance with the OM observations that all the alloys RUEed under different starting temperatures exhibited the typical bimodal microstructure, the fine DRXed grains showed almost random crystallographic orientation, and an evident color gradient could be seen in many large grains, which suggested that sub-grain boundaries and dense dislocations in the large grains induced the occurrence of misorientation.

Figure $6 \mathrm{~b}, \mathrm{c}$ show the point-to-point misorientations, $\Delta \theta$, and point-to-origin misorientations, $\sum \Delta \theta$, along the arrows $\mathrm{AB}$ and $\mathrm{CD}$. The misorientation increased gradually up to 16 owing to the lattice rotation relative to the origin point. However, some DRXed grains also formed along the LABs, marked by the white arrows (Figure 6a). Usually, LAGBs result from the accumulation of dislocations and formation of sub-GBs in the large grains $[33,34]$. With the increasing strain, these LAGBs trapped more mobile dislocations and transformed themselves into HAGBs, ultimately turning sub-grains into DRXed grains, which indicated the operation of CDRX. DRX relied on the morphologies of the second phases. It was verified that large second phases enhance the accumulation of strain gradient during deformation, which is necessary for the PSN mechanism to operate [27]. In addition, as indicated by the black arrows, bulges could be observed along the initial coarse boundary. The size of the bulges was equal to that of the DRXed grains, which indicates that DDRX also took place during RUE processing. 
(a)

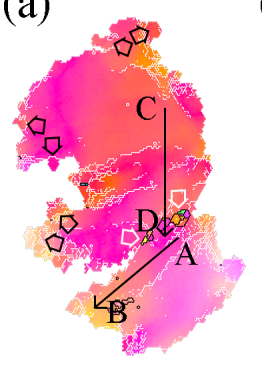

(b)

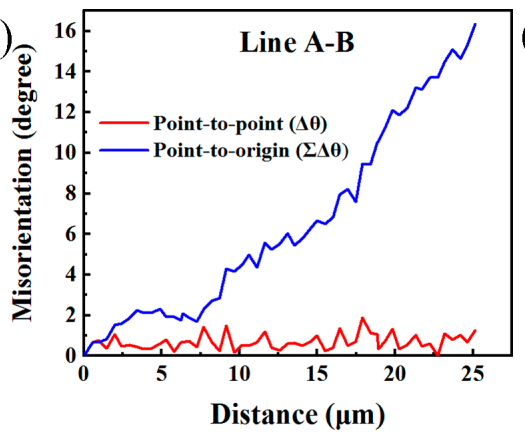

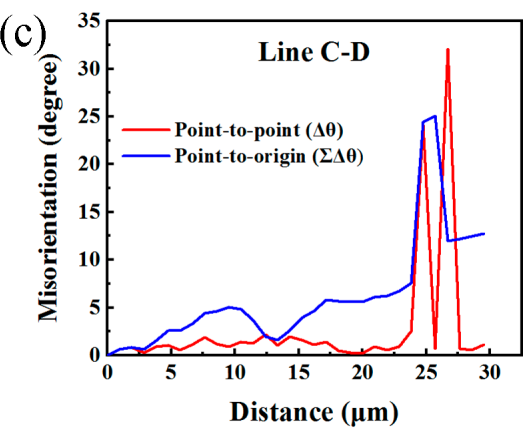

Figure 6. (a) Extracted grains from the edge of sample \#2 (highlighted by yellow dashed boxes in Figure $5 b)$, and $(\mathbf{b}, \mathbf{c})$ show the typical point-to-point and point-to-origin misorientations along lines $\mathrm{AB}$ and CD marked in (a).

Figure 7a-c present the $(0001)<11-20>$ Schmid factor distribution maps of the edge of sample \#1, $\# 2$ and \#3. The peak value of the $(0001)<11-20>$ Schmid factor was mainly distributed around 0.45 . Texture evaluation of the RUEed alloys under different starting temperatures, the (0001) and (10-10) pole figures are presented in Figure 7d-f. It was found that all the alloys presented the (0001) planes parallel to the RUE direction, which is the typical extrusion texture of Mg alloy. The effects of deformed and DRXed grains on the texture of the alloys RUEed under different starting temperatures were similar. The OIM maps and corresponding pole figures in the deformed and DRXed grains of sample \#3 are partitioned (Figure 8). The deformed grains had a stronger basal texture (Figure 8c), but the (0001) pole figures distribution of the DRXed grains was rather dispersive (Figure 8d). The maximum basal texture intensity of DRXed grains was only 1.5, and the texture randomization associated with PSN of recrystallization has been reported in the $\mathrm{Al}$ alloys [35] and Mg alloys [36]. Therefore, the high volume fraction of DRXed grains could weaken the texture. Such DRXed grains could shorten the slip distance of the dislocations, which led to the release of stress concentration at the grain boundaries, and enhanced the ductility of the alloys. The bimodal microstructure had a similar effect on the mechanical properties of the extruded Mg-Zn-Y alloys [37]: The deformed grains showed strong texture, which together with the LPSO phases, can strengthen the alloys. However, the DRXed grains exhibited weak texture, which can enhance the ductility.
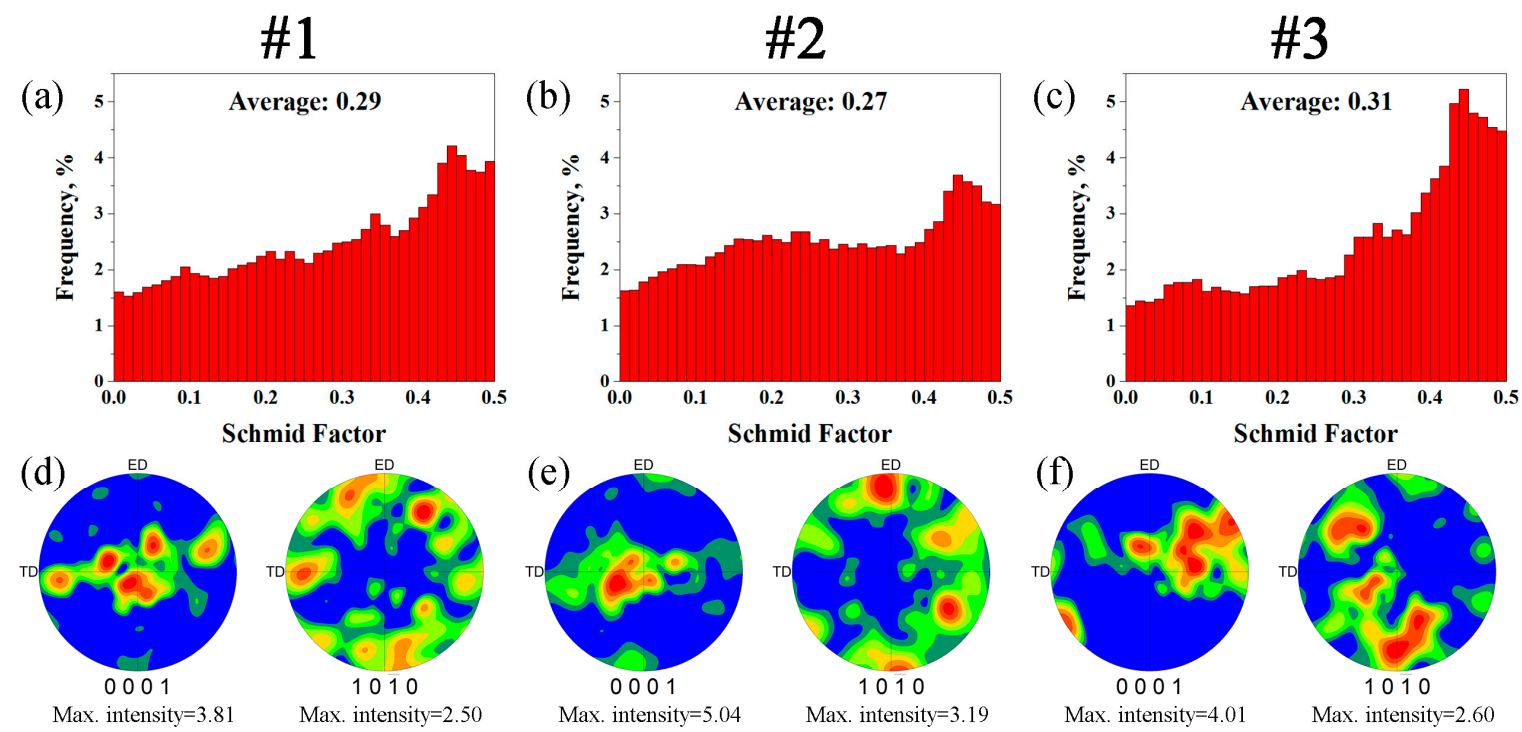

Figure 7. $(0001)<11-20>$ Schmid factor distribution histograms $(\mathbf{a}-\mathbf{c})$ and pole figures $(\mathbf{d}-\mathbf{f})$ of the edge of sample \#1 (a,d), \#2 (b,e) and \#3 (c,f). 


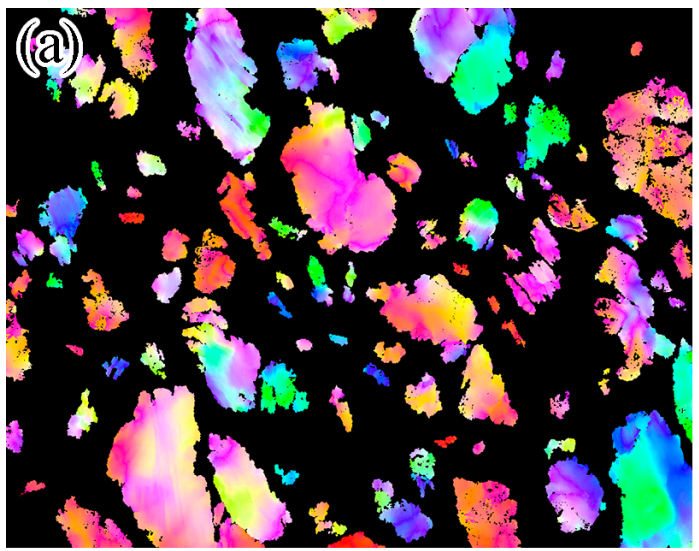

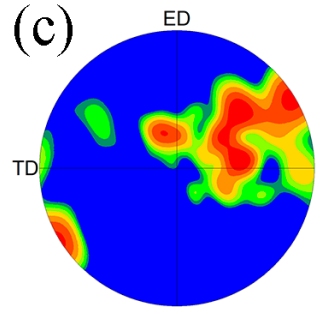

0001

Max. intensity=7.39

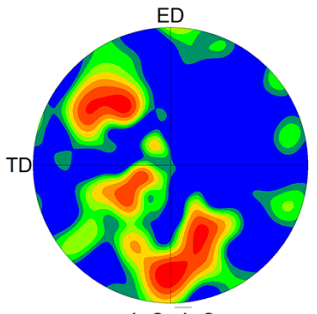

1010

Max. intensity $=4.47$

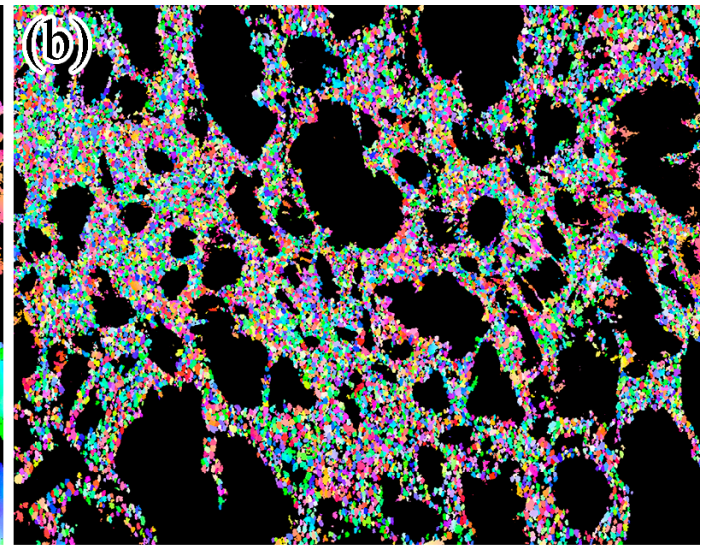

(d)

ED

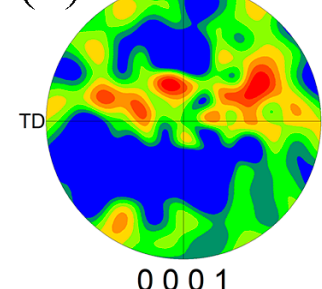

Max. intensity $=1.53$

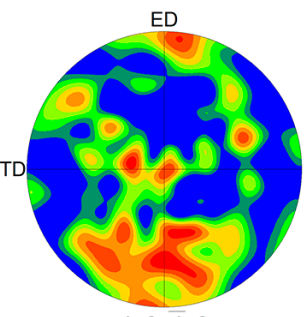

$10 \overline{10}$

Max. intensity $=1.22$

Figure 8. OIM maps and corresponding EBSD-derived pole figures of the edge of the sample \#3: (a,c) deformed grains; $(\mathbf{b}, \mathbf{d})$ DRXed grains.

\section{Conclusions}

1. The as-cast alloy consisted of $\alpha-\mathrm{Mg}$, fine-lamellar phases and eutectics. After homogenization, there was no obvious grain growth owing to the pinning effect produced by the block-shaped phases. $\mathrm{Mg}_{5}(\mathrm{Gd}, \mathrm{Y}, \mathrm{Zn})$ belonged to network eutectics and $\mathrm{Mg}_{12}(\mathrm{Gd}, \mathrm{Y}) \mathrm{Zn}$ belonged to blockshaped phases.

2. The oriented fine-lamellar phases and particle phases dynamically precipitated during repetitive upsetting extrusion (RUE). The particles and second phases induced dynamic recrystallization (DRX), which can be explained by the particle-stimulated nucleation (PSN) mechanism. The samples from the center of the longitudinal section exhibited a coarser structure than those taken from the edge.

3. The RUEed alloys under different starting temperatures exhibited the typical bimodal distribution; the deformed grains showed strong texture and the DRXed grains showed weak texture. The grain refinement mechanisms of RUEed alloys were caused by continuous dynamic recrystallization (CDRX) and discontinuous dynamic recrystallization (DDRX). The DRXed grains could weaken the texture. With a decrease in the RUE starting temperatures, the average grain size and the precipitation of particle phases increased and the volume fraction of DRXed grains decreased.

Author Contributions: Conceptualization, G.Z. and Z.Z.; Methodology, Z.Z.; Software, Y.M. and X.C.; Investigation, all authors; Writing-Original Draft Preparation, G.Z.; Writing-Review and Editing, G.Z., Z.Y., and X.L.

Funding: This research was funded by Natural Science Foundation of Shanxi Province, grant number 201801D121106.

Conflicts of Interest: The authors declare no conflict of interest. 


\section{References}

1. Fiedrich, H.; Shumann, S. Research for a "new age of magnesium" in the automotive industry. J. Mater. Process. Technol. 2001, 117, 276-281. [CrossRef]

2. Wang, R.M.; Eliezer, A.; Gutman, E. Microstructures and dislocations in the stressed AZ91D magnesium alloys. Mater. Sci. Eng. A 2002, 344, 279-287. [CrossRef]

3. Xu, C.; Xu, S.W.; Zheng, M.Y.; Wu, K.; Wang, E.D.; Kamado, S.; Wang, G.J.; Lv, X.Y. Microstructures and mechanical properties of high-strength $\mathrm{Mg}-\mathrm{Gd}-\mathrm{Y}-\mathrm{Zn}-\mathrm{Zr}$ alloy sheets processed by severe hot rolling. J. Alloys Compd. 2012, 524, 46-52. [CrossRef]

4. Wang, L.; Zhao, Y.Q.; Chen, H.M.; Zhang, J.; Liu, Y.D.; Wang, Y.N. Improvement of mechanical properties of magnesium alloy ZK60 by asymmetric reduction rolling. Acta Metall. Sin. Engl. Lett. 2017, 31, 63-70. [CrossRef]

5. Xia, X.S.; Zhang, K.; Li, X.G.; Ma, M.L.; Li, Y.J. Microstructure and texture of coarse-grained Mg-Gd-Y-Nd-Zr alloy after hot compression. Mater. Des. 2013,44, 521-527. [CrossRef]

6. Du, B.N.; Hu, Z.Y.; Sheng, L.Y.; Xu, D.K.; Zheng, Y.F.; Xi, T.F. Influence of Zn content on microstructure and tensile properties of Mg-Zn-Y-Nd alloy. Acta Metall. Sin. Engl. Lett. 2018, 31, 351-361. [CrossRef]

7. Wang, X.J.; Xu, D.K.; Wu, R.Z.; Chen, X.B.; Peng, Q.M.; Jin, L.; Xin, Y.C.; Zhang, Z.Q.; Liu, Y.; Chen, X.H.; et al. What is going on in magnesium alloys. J. Mater. Sci. Technol. 2018, 34, 245-247. [CrossRef]

8. Aizawa, T.; Tokumitsu, K. Bulk mechanical alloying for productive processing of functional alloys. Mater. Sci. Forum 1999, 312-314, 13-22. [CrossRef]

9. Zhang, Z.M.; Du, Y.; Zhang, G.S.; Yan, Z.M.; Yu, J.M.; Meng, M. Microstructure and mechanical properties of Mg-Gd-Y-Zn-Zr alloy prepared by repetitive upsetting and extrusion. Mater. Trans. 2018, 59, 669-673. [CrossRef]

10. Hu, L.X.; Li, Y.P.; Wang, E.D.; Yu, Y. Ultrafine grained structure and mechanical properties of a LY12 Al alloy prepared by repetitive upsetting-extrusion. Mater. Sci. Eng. A 2006, 422, 327-332.

11. Xu, Y.; Hu, L.X.; Sun, Y.; Jia, J.B.; Jiang, J.F.; Ma, Q.G. Microstructure and mechanical properties of AZ61 magnesium alloy prepared by repetitive upsetting-extrusion. Trans. Nonferrous Met. Soc. China 2018, 25, 381-388. [CrossRef]

12. Xu, Y.; Chen, C.; Jia, J.B.; Zhang, X.X.; Dai, H.H.; Yang, Y. Constitutive behavior of a SIMA processed magnesium alloy by employing repetitive upsetting-extrusion (RUE). J. Alloys Compd. 2018, 748, 694-705. [CrossRef]

13. Liu, X.; Zhang, Z.Q.; Hu, W.Y.; Le, Q.C.; Bao, L.; Cui, J.Z. Effects of extrusion speed on the microstructure and mechanical properties of Mg-9Gd-3Y-1.5Zn-0.8Zr alloy. J. Mater. Sci. Technol. 2016, 32, 313-319. [CrossRef]

14. Zhang, D.X.; Tan, Z.; Huo, Q.H.; Xiao, Z.Y.; Fang, Z.W.; Yang, X.Y. Dynamic recrystallization behaviors of Mg-Gd-Y-Zn-Zr alloy with different morphologies and distributions of LPSO phases. Mater. Sci. Eng. A 2018, 715, 389-403. [CrossRef]

15. Zhang, J.H.; Xu, C.; Jing, Y.B.; Lv, S.H.; Liu, S.J.; Fang, D.Q.; Zhuang, J.P.; Zhang, M.L.; Wu, R.Z. New horizon for high performance $\mathrm{Mg}$-based biomaterial with uniform degradation behavior: formation of stacking faults. Sci. Rep. 2015, 5, 13933. [CrossRef] [PubMed]

16. Shao, X.H.; Yang, Z.Q.; Ma, X.L. Strengthening and toughening mechanisms in Mg-Zn-Y alloy with a long period stacking ordered structure. Acta Mater. 2010, 58, 4760-4771. [CrossRef]

17. Hagihara, K.; Kinoshita, A.; Sugino, Y.; Yamasaki, M.; Kawamura, Y.; Yasuda, H.Y.; Umakoshi, Y. Effect of long-period stacking ordered phase on mechanical properties of Mg97Zn1Y2 extruded alloy. Acta Mater. 2010, 58, 6282-6293. [CrossRef]

18. Yang, J.; Peng, J.; Li, M.; Nyberg, E.A.; Pan, F.S. Effects of Ca addition on the mechanical properties and corrosion behavior of ZM21 wrought alloys. Acta Metall. Sin. Engl. Lett. 2016, 30, 53-65. [CrossRef]

19. Hagihara, K.; Yokotani, N.; Umakoshi, Y. Plastic deformation behavior of $\mathrm{Mg}_{12} \mathrm{YZn}$ with $18 \mathrm{R}$ long-period stacking ordered structure. Intermetallics 2010, 18, 267-276. [CrossRef]

20. Yamasaki, M.; Hagihara, K.; Inoue, S.; Hadorn, J.P.; Kawamura, Y. Crystallographic classification of kink bands in an extruded Mg-Zn-Y alloy using intragranular misorientation axis analysis. Acta Mater. 2013, 61, 2065-2076. [CrossRef]

21. Homma, T.; Kunito, N.; Kamado, S. Fabrication of extraordinary high-strength magnesium alloy by hot extrusion. Scr. Mater. 2009, 61, 644-647. [CrossRef] 
22. Xu, C.; Zheng, M.Y.; Xu, S.W.; Wu, K.; Wang, E.D.; Kamado, S.; Wang, G.J.; Lv, X.Y. Ultra high-strength Mg-Gd-Y-Zn-Zr alloy sheets processed by large-strain hot rolling and ageing. Mater. Sci. Eng. A 2012, 547, 93-98. [CrossRef]

23. Wan, Q.D.; Chen, Y.J.; Liu, M.P.; Lin, J.B.; Roven, H.J. Microstructure evolution of AZ series magnesium alloys during cyclic extrusion compression. Mater. Sci. Eng. A 2010, 527, 2265-2273.

24. Xu, C.; Zheng, M.Y.; Chi, Y.Q.; Chen, X.J.; Wu, K.; Wang, E.D.; Fan, G.H.; Yang, P.; Wang, G.J.; Lv, X.Y.; et al. Microstructure and mechanical properties of the $\mathrm{Mg}-\mathrm{Gd}-\mathrm{Y}-\mathrm{Zn}-\mathrm{Zr}$ alloy fabricated by semi-continuous casting. Mater. Sci. Eng. A 2012, 549, 128-135. [CrossRef]

25. Liu, H.; Xue, F.; Bai, J.; Ma, A.B.; Jiang, J.H. Formation behavior of $14 \mathrm{H}$ long period stacking ordered structure in Mg-Y-Zn cast alloys with different $\alpha-\mathrm{Mg}$ fractions. J. Mater. Sci. Technol. 2016, 32, 1267-1273. [CrossRef]

26. Zhou, X.J.; Liu, C.M.; Gao, Y.H.; Jiang, S.N.; Liu, W.H.; Lu, L.W. Hot compression behavior of the Mg-Gd-Y-Zn-Zr alloy filled with intragranular long-period stacking ordered phases. J. Alloys Compd. 2017, 724, 528-536. [CrossRef]

27. Robson, J.D.; Henry, D.T.; Davis, B. Particle effects on recrystallization in magnesium-manganese alloys: Particle-stimulated nucleation. Acta Mater. 2009, 57, 2739-2747. [CrossRef]

28. Guo, W.; Wang, Q.D.; Ye, B.; Zhou, H. Microstructure and mechanical properties of AZ31 magnesium alloy processed by cyclic closed-die forging. J. Alloys Compd. 2013, 558, 164-171. [CrossRef]

29. Li, L. Deformation band and texture of a cast Mg-RE alloy under uniaxial hot compression. Mater. Sci. Eng. A 2011, 528, 7178-7185. [CrossRef]

30. Al-Samman, T.; Gottstein, G. Dynamic recrystallization during high temperature deformation of magnesium. Mater. Sci. Eng. A 2008, 490, 411-420. [CrossRef]

31. Xu, S.W.; Kamado, S.; Honma, T. Recrystallization mechanism and the relationship between grain size and Zener-Hollomon parameter of Mg-Al-Zn-Ca alloys during hot compression. Scr. Mater. 2010, 63, $293-296$. [CrossRef]

32. Xu, S.W.; Kamado, S.; Matsumoto, N.; Honma, T.; Kojima, Y. Recrystallization mechanism of as-cast AZ91 magnesium alloy during hot compressive deformation. Mater. Sci. Eng. A 2009, 527, 52-60. [CrossRef]

33. Xin, Y.C.; Wang, M.Y.; Zeng, Z.; Huang, G.J.; Liu, Q. Tailoring the texture of magnesium alloy by twinning deformation to improve the rolling capability. Scr. Mater. 2011, 64, 986-989.

34. Luo, J.; Hu, W.W.; Jin, Q.Q.; Yan, H.; Chen, R.S. Unusual cold rolled texture in an Mg-2.0Zn-0.8Gd sheet. Scr. Mater. 2017, 127, 146-150. [CrossRef]

35. Humphreys, F.J. The nucleation of recrystallization at second phase particles in deformed aluminium. Acta Metall. 1977, 25, 1323-1344. [CrossRef]

36. Ball, E.A.; Prangnell, P.B. Tensile-compressive yield asymmetries in high strength wrought magnesium alloys. Scr. Metall. 1994, 31, 111-116. [CrossRef]

37. Yamasaki, M.; Hashimoto, K.; Hagihara, K.; Kawamura, Y. Effect of multimodal microstructure evolution on mechanical properties of Mg-Zn-Y extruded alloy. Acta Mater. 2011, 59, 3646-3658. [CrossRef]

(C) 2019 by the authors. Licensee MDPI, Basel, Switzerland. This article is an open access article distributed under the terms and conditions of the Creative Commons Attribution (CC BY) license (http://creativecommons.org/licenses/by/4.0/). 